\title{
GENETIC DIVERSITY OF HONEYBEE (APIS MELLIFERA ADANSONII) IN IJEBU ENVIRONAS REVEALED BY SIMPLE SEQUENCE REPEAT (SSR) MARKERS
}

*Adeleke, Mistura Temitope ${ }^{1}$; Adekunle, Oladunni Nimota ${ }^{1}$; Owagboriaye, Folarin Ojo ${ }^{1}$; Odeseye Adebola Olayemi'; ${ }^{2}$ Oyedele, Kemi Sarah ${ }^{1 ;}$ Adebowale, Afolashade Abosede ${ }^{1}$; Orindare, Feranmi Tolulope'; Johnson, Damilola ${ }^{1}$., and Lawal, Olusegun Adebayo'.

'Department of Zoology and Environmental Biology, Olabisi Onabanjo, P.M.B 2002 Ago-Iwoye, Ogun State, Nigeria

'Department of Biological Sciences, Nigerian Institute of Science Laboratory Technology, Samonda, Ibadan, Oyo State, Nigeria.

*Corresponding author: adeleke.mistura@oouagoiwoye.edu.ng

\section{ABSTRACT}

Honeybee Apis mellifera adansonii, dominant honey producing species in Nigeria was subjected to genetic variability studies using Simple Sequence Repeat (SSR) in other to provide the baseline dat in Nigeria. Nine (9) Simple Sequence Repeats (SSR) primers were used to assess the genetic diversity in Two (2) worker bees each collected from 22 colonies found in the four apiaries in Ijebu environs of Ogun State. Data collected were subjected to analysis and results showed that six (6) out of nine
primers produced 80 reproducible, polymorphic bands while the remaining three (3) were primers produced 80 reproducible, polymorphic bands while the remaining three (3) were populations ( FST) was 0.430 and 0.340 , respectively. Analysis of Molecular Variance (AMOVA) partitioned the total genetic variation as $70 \%$ within, $30 \%$ among populations. The cluster analysis showed that Ipari-Oke 3 and Odo-Epo 1-8 populations diverged from others which showed they are closer in genetic distances while Ipari-Oke 1 and Odo-Epo 2-5 were newly observed subcluster which represents another subspecies. In conclusion, genetic variations existed amongst the honey worker bees populations in Ogun State.

Keywords: Apis mellifera adansonii, Genetic Diversity, Honeybee, Ijebu, SSR Markers

Accepted Date: 1 June 2020

\section{INTRODUCTION}

Bees are a specialized type of flying insects that can be described as a key component of global diversity. They are very much like the wasps, ants and are known for honey production, bee wax, royal jelly and propolis (Woodley et al., 2015). They are a crucial part of ecosystems, pollinating one-third of food consumed by humans, increase the biodiversity of plants species, maintain genetic diversity within plants populations, increase fruit yields and hence support flora and fauna in every level of the food chain (Batra,1995). The Honeybees which belong to the family Apidae are naturally distributed in Africa, Europe and Western Asia (Ostroverkhova et al., 2017). Currently, 28
Honeybees morphologic structures showed various adaptations for foraging, nectar collection, feeding the queen and the larvae, cleaning brood cells; removing debris, honey and pollen storage and rearing of larvae in cells made from wax secreted by the worker bees. Several works with Apis mellifera involving morphologic characters and weight showed that there is a strong influence of the environment in the morphology of the same of the (Aboushar species (Aboushara et al, 2012). Furthermore, there is often a positive correlation in some characteristics, for instance, the length of the wing and altitude, the size of pollen basket and hind-leg and the size of the honey stomach and honey production and storage. Such correlation can indicate the importance of the morphologic characteristics in the adaptation of individuals to the environment (Ajao, 2012).

Due to the continuous challenges of morphometric studies, molecular level studies began with the help of allozymes (Allelic form of an enzyme that can be distinguished by gel electrophoresis to observe genetic variation from gene products), mitochondrial DNA (mtDNA) (Hunt \& Page 1992, Rinderer et al. 1995) and microsatellites (Strange etal. 2008). Protein and enzyme polymorphism in . Proved to be useful in development studies, population genetics and classification (Arias, et al., 2006). Different DNA analysis methods have been applied to clarify the race standard of the local honeybee (Ivanova et al., 2010). Some markers like randomly amplified polymorphic DNA (RAPD) can produce multiple bands fragments. These fragments are usually generated from different regions of the genome and hence multiple loci maybe examined very quickly (Kumar \& Gurusubramanian, 2011).

A variety of molecular markers have been used in honeybee as reported by Hunt \& Page, (1992), Tunca \& Kence, (2006) and Whitfield et al.,(2006). However, PCR-based markers are more appropriate for fingerprinting studies such as random amplified polymorphic DNA (RAPD), simple sequence repeats (SSR) and the inter simple sequence repeat (ISSR). Furthermore, micro satellite markers play an important role in determining genetic diversity and phylogenetic relationships of animals and especially insects (Rahimi et al., 2014) that promotes homeostasis in insect colonies (Oldroyd \& Fewell, 2007). Studies have shown that genetically diverse honey bee colonies are more productive, fit, have increased colony growth and are less susceptible to severe infections (Bienefeld, 2016). There has been paucity of data on genetic studies of honey bees in Ogun State. This work aims to determine the genetic variability of worker bee samples from 22 colonies in some areas in Ijebu environs in Ogun State, Nigeria using SSR markers.

\section{MATERIALS AND METHODS}

\section{Study Area:}

A total of 44 Samples of honeybees were collected from four different locations of available honeybee farms (Odo-Epo Bee farm 1; Odo-Epo Bee farm 2; Ipari-Oke Bee farm 1 and Bee farm - P S Biomes) in Ijebu environs of Ogun State, Southwestern Nigeria. Consent of approval was sought from the bee farmers from the 4 apiaries before the beginning of the study. A total of 22 colonies were found in the apiaries (Odo-Epo Bee farm 1 (Eight colonies); Odo-Epo Bee farm 2 (Eight colonies); Ipari-Oke Bee farm 1 (Three colonies); Bee farm - P S Biomes (Three colonies). Two (2) worker honeybee samples were taken from 22 colonies in the study area and preserved carefully in well-labelled specimen bottles cont bottles containg $70 \%$ alcohol. These samples were trige to the biotechnology laboratory of Nigeria Institute of Science and Laboratory Technology (NIST), Samonda, Ibadan in Oyo State, Nigeria to undergo molecular analysis which included DNA extraction and amplification.

\section{DNAEXTRACTION:}

The DNA of honeybees was extracted using modified Cetyl trimethylammonium bromide (CTAB) extraction procedure according to Murray $\&$ Thompson (1980) and DNA was quantified using the ultraviolet spectrophotometer for quality assessment.

\section{DNA AMPLIFICATION}

Nine (9) SSR markers namely LA1, A7, A81, A29, A113, A107, A14, IC1 and B124 (Table 1) were used to amplify the extracted DNA samples. PCR was performed according to Solignac et al., (2003). The amplification products were resolved by electrophoresis in $6.0 \%$ polyacrylamide gel with a 1.0 X TBE buffer. After electrophoresis, gels were stained with ethidium bromide solution. 
TABLE 1: The List of Primers and Its Sequences

\begin{tabular}{lll}
\hline $\mathbf{S} / \mathbf{N}$ & LOCUS & SEQUENCE OF PRIMERS \\
\hline 1 & A81F & 5'-GCCGAGTTCTTCGACTCCC-3' \\
& A81R & 5'-GGACTTTGCCAAATGGGTC-3' \\
2 & IC1F & 5'-GGTTTGATGCTCGTAAGGG-3' \\
& ICIR & 5'-GGCACCTCTTGCCATCTG-3' \\
3 & A7F & 5'-GTTAGTGCCCTCCTCTTGC-3' \\
& A7R & 5'-CCCTTCCTCTTTCATCTTCC-3' \\
4 & A113F & 5'-CTCGAATCGTGGCGTCC-3' \\
& A113R & 5'-CCTGTATTTTGCAACCTCGC-3' \\
5 & B124F & 5'-GCAACAGGCGGGTTAGAG-3' \\
& B124R & 5'-CAGGATAGGGTAGGTAAGAG-3' \\
6 & A107F & 5'-CCGTGGGAGGTTTATTGTCG-3' \\
7 & A107R & 5'-CCTTCGTAACGGATGACACC-3' \\
7 & A14F & 5'-GTGTCGCAATCGACGTAACC-3' \\
& A14R & 5'-GTCGATTACCGATCGTGACG-3' \\
8 & A29F & 5'-AAACAGTACATTTGTGACCC-3' \\
& A29R & 5'-CAACTTCAACTGAAATCCG-3' \\
9 & LA1F & 5'-GAGAGAGAGAGAGAGACG-3' \\
& LA1R & 5'-ACACACACACACACACAT-3' \\
\hline
\end{tabular}

\section{DATA ANALYSIS}

Polymorphic bands were scored as present (1) or absent (0) for SSR analyses. Percent of polymorphic bands, expected heterozygosity (He), gene diversity (Nei, 1973) and Shannon's information indices $(I)$ (Lewontin, 1972) were calculated using the following equation

$$
I=\Sigma p i \ln p i
$$

where $p i$ stands for the proportion of the $i$ th allele in the population.

Pairwise $\mathrm{F}_{\mathrm{ST}}$ was calculated using POPGENE 1.31 software (Yeh et al., 1999). The total band patterns, and Analysis of Molecular Variance (AMOVA), were carried out using Genalex6 software program (Peakall\&Smouse, 2006). UPGMA tree was constructed based on original distance using TFPGA v.13 (Miller, 1997). Factorial Analysis was performed using NTSYS v.2.20 Antysise program (Rohlf, 2000).

\section{RESULTS}

Nine (9) SSR markers were screened out of which six (6) were polymorphic, hence 6 polymorphic primers were used for the final analysis of honeybees i.e. A81, A29, A113, A107, A14 and IC1 markers amplified 80 polymorphic bands (Figure 1).

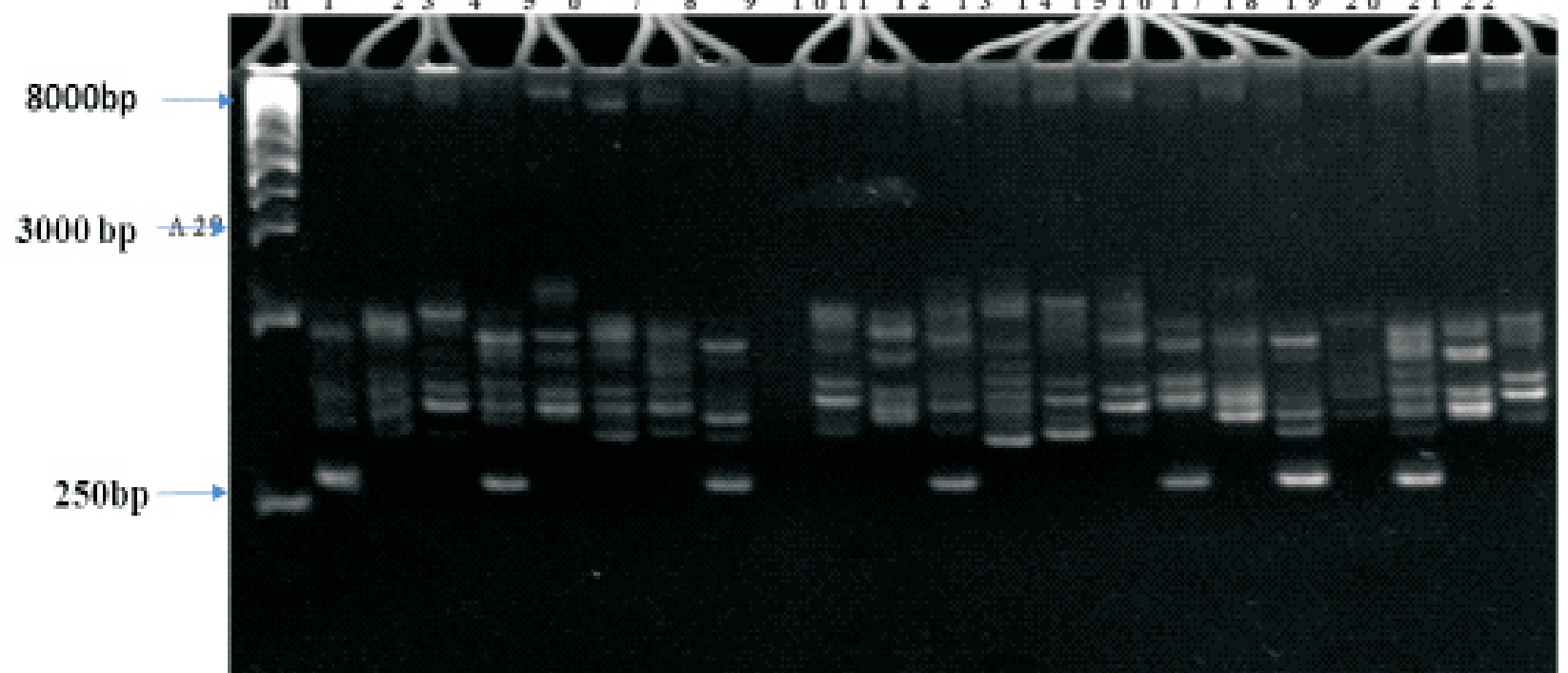

Figure 1: A29 primer plate showing polymorphic bands

The percentage of polymorphic loci ranged between $13 \%$ and $54 \%$ in populations of PS Biome2 and Ipari- Oke1 respectively. The proportion of polymorphic bands expected heterozygosity (He), Shannon's information index (I) values are given in Table 2. The expected heterozygosity levels for honeybee populations ranged between 0.054 (Odo-Epo 1-8) and 0.19 (Ipari-Oke1). Gene diver Ipari-Oke1). Gene diversity and Shannon's index values for all populations were estimated to be 0.11 and 0.14 , respectively.

The most informative primers were A29 and A113, they have the highest number of expressed bands (161 and 130 respectively) in 16 loci. The locations with the highest number of polymorphic expressions were Ipari-Oke 1(48 bands), OdoEpo1-1 (36 bands) and Ipari-O the lowest expression was observed in PS biome2 population (Table 2). Gene diversity $\left(H_{T}\right)$ in total population and magnitude of differentiation among populations (FST) was 0.430 and 0.340 , respectively. Analysis of $\mathrm{Mol}$ (AMOVA) partitioned the total genetic variation as $70 \%$ within, $30 \%$ among populations Pairwise $F S T$ values were given in Table 3, while the highest pairwise $F S T$ was observed between Ipari-Oke 1 and PS Biome2 (0.552), the lowest was detected between IpariOke2 and Odo-Epo 2-8 populations (0.016). 
Table 2: Observed number of bands, percentage of polymorphic bands, expected heterozygosity $\left(\mathrm{H}_{\mathrm{e}}\right)$ and Shannon's information index $(I)$ values for populations studied.

ACC Observed bands \% Polymorphic $\mathrm{H}_{\mathrm{e}} \quad I$

\begin{tabular}{llccc}
\hline Ep 1-1 & 36 & 45 & 0.150 & 0.180 \\
Ep 1-2 & 23 & 29 & 0.100 & 0.134 \\
Ep 1-3 & 32 & 40 & 0.160 & 0.167 \\
Ep 1-4 & 17 & 21 & 0.100 & 0.109 \\
Ep 1-5 & 28 & 35 & 0.120 & 0.153 \\
Ep 1-6 & 31 & 39 & 0.140 & 0.164 \\
Ep 1-8 & 12 & 15 & 0.054 & 0.084 \\
Ep 1-9 & 16 & 20 & 0.080 & 0.104 \\
Ep 2-1 & 30 & 38 & 0.134 & 0.160 \\
Ep 2-2 & 25 & 31 & 0.110 & 0.142 \\
Ep 2-3 & 26 & 33 & 0.120 & 0.146 \\
Ep 2-5 & 19 & 24 & 0.080 & 0.117 \\
Ep 2-6 & 22 & 28 & 0.100 & 0.130 \\
Ep 2-7 & 17 & 21 & 0.080 & 0.109 \\
Ep 2-8 & 26 & 33 & 0.110 & 0.146 \\
Ep 2-9 & 26 & 33 & 0.100 & 0.146 \\
Ip 1 & 43 & 54 & 0.190 & 0.201 \\
Ip 2 & 28 & 35 & 0.130 & 0.153 \\
Ip 3 & 36 & 45 & 0.170 & 0.180 \\
Ps 1 & 25 & 31 & 0.110 & 0.142 \\
Ps 2 & 10 & 13 & 0.060 & 0.074 \\
Ps 3 & 14 & 18 & 0.070 & 0.094 \\
\hline ACCCODE: Ep 1- Odo-Epo farm 1; Ep 2- Odo-Epo farm 2; Ip - Ipari-Oke farm; Ps - PS Biome
\end{tabular}

The dendrogram in Figure 3 indicated no unique The factorial analysis of the worker bee samples clusters based on location but Ipari-Oke 3 and OdoEpo-1-8 populations diverged from all other populations. Within superclusters, Odo-Epo and PS Biome formed a subcluster from the populations that shows relativeness in the honeybee samples PSB emerging subcluster which tends to represent another subspecies.
Table 3: Pairwise $F S T$ v alues among four populations.

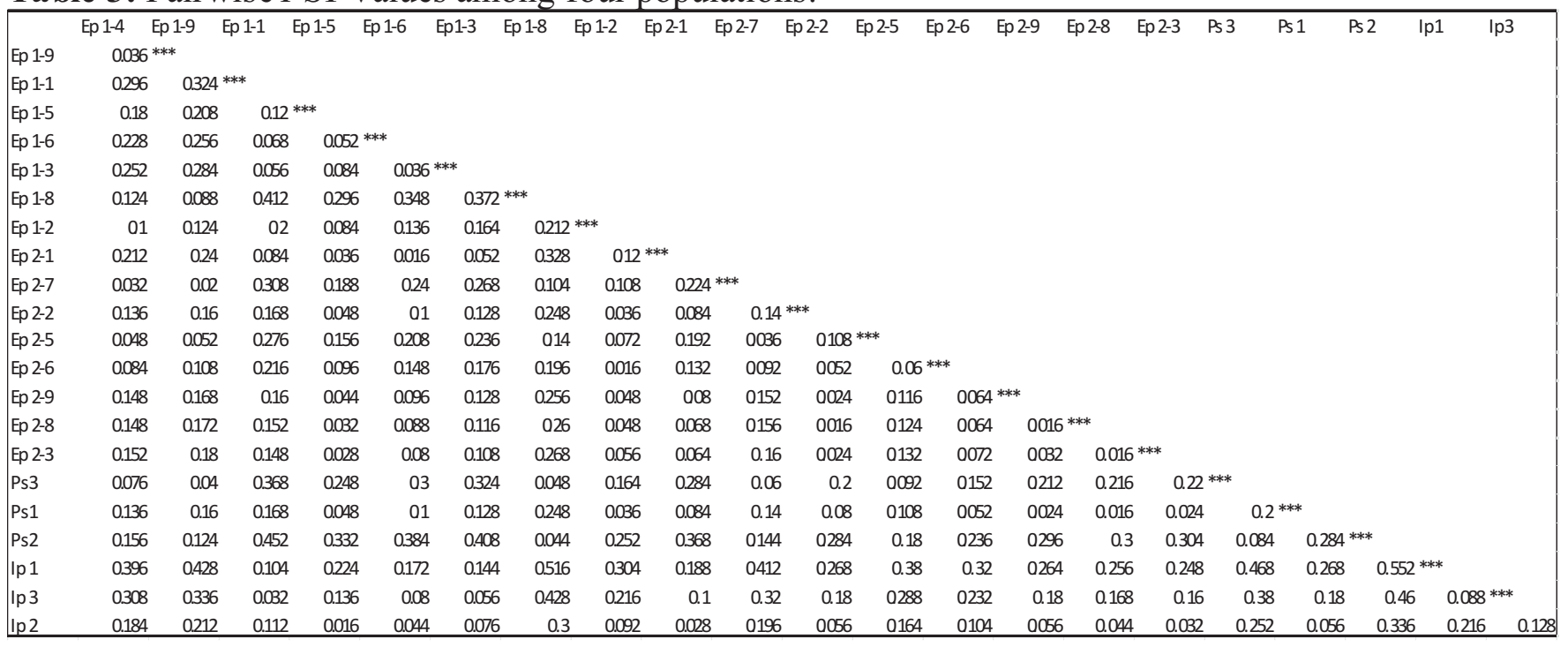

Code name: Ep 1- Odo-Epo farm1; Ep 2- Odo-Epo farm 2; Ip - Ipari-Oke farm; Ps - PS Biome

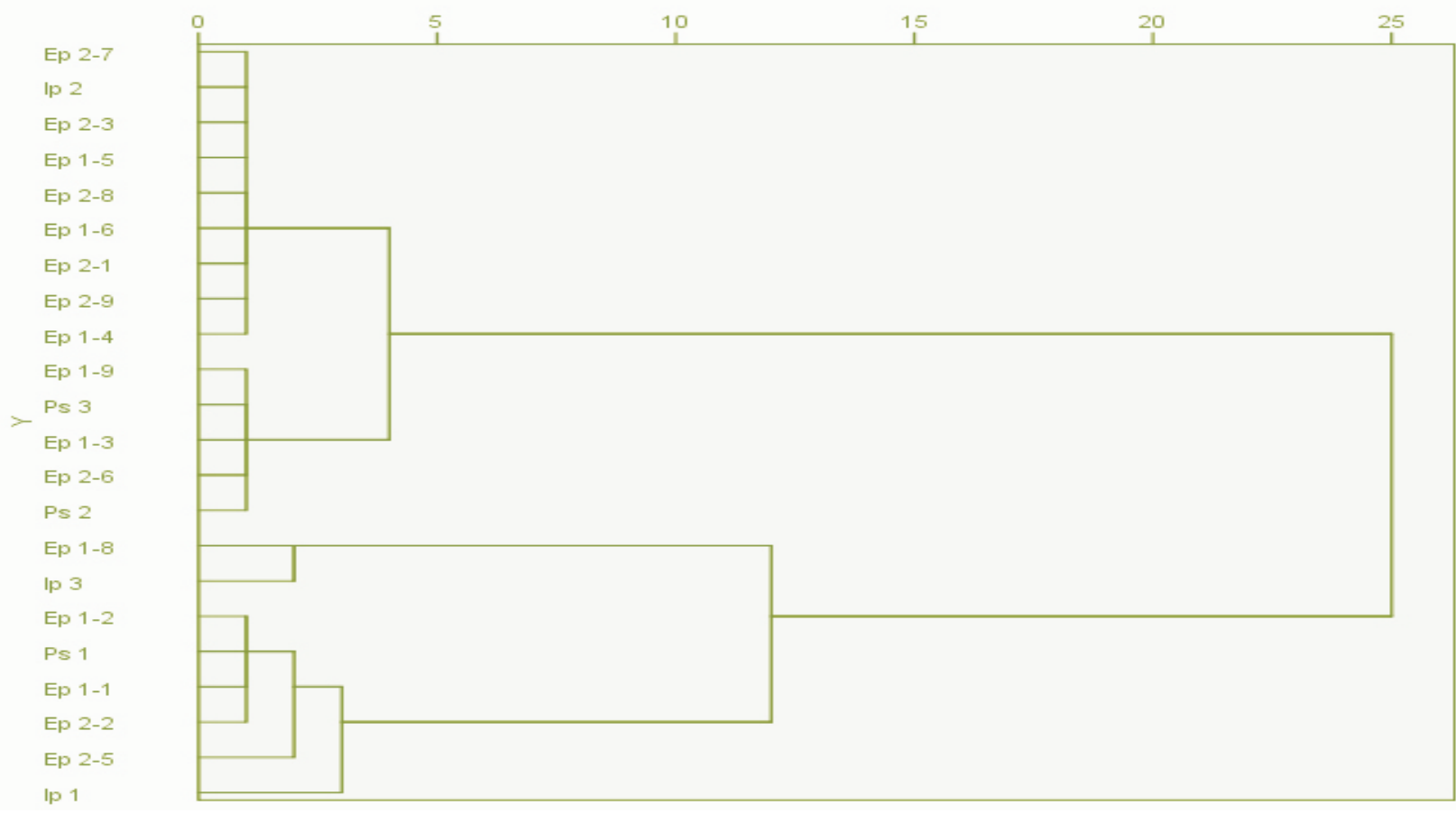

Figure 3 :Dendro gram showing the relationship between honeybee samples from Ijebu environ. Code name: Ep 1-Odo-Epo farm 1; Ep 2- Odo-Epo farm 2; Ip - Ipari-Oke farm; Ps - PS Biome 


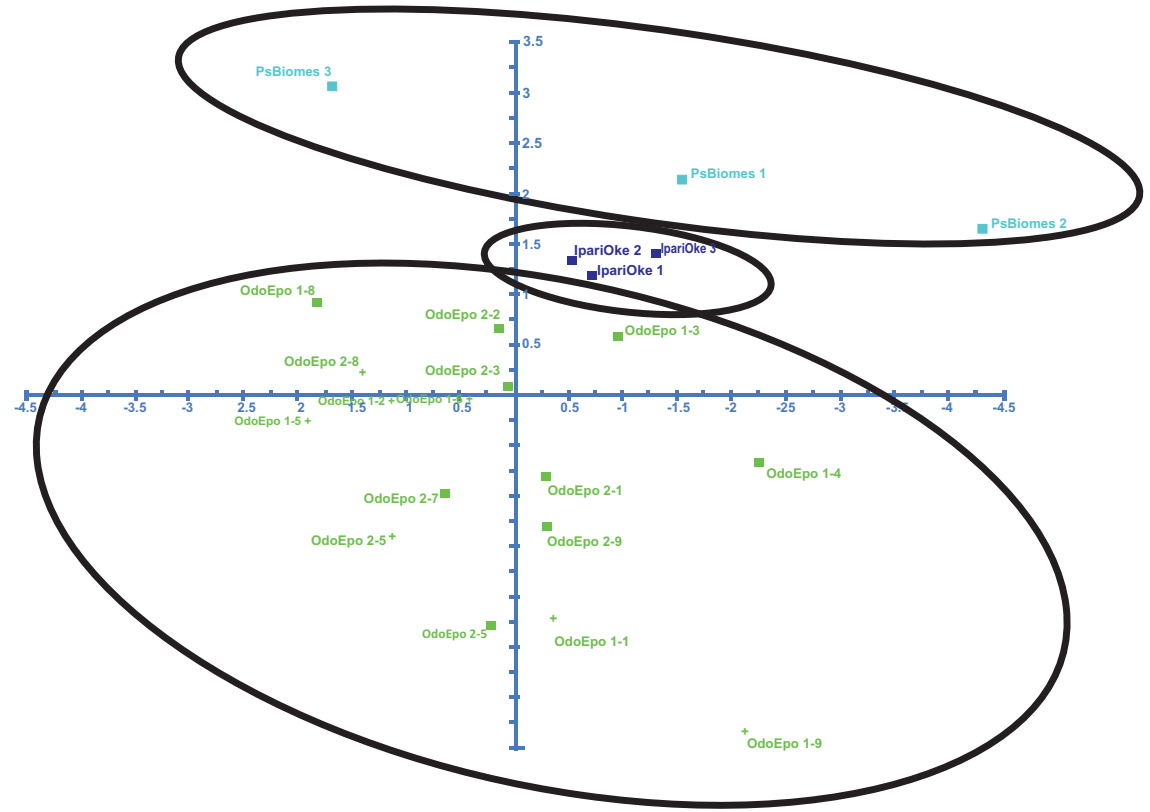

Figure 4a: Factorial analysis of worker hon eybees samples based on their locations Code name: Ep 1- Odo-Epo farm 1; Ep 2- Odo-Epo farm 2; Ip - Ipari-Oke farm; Ps - PS Biome

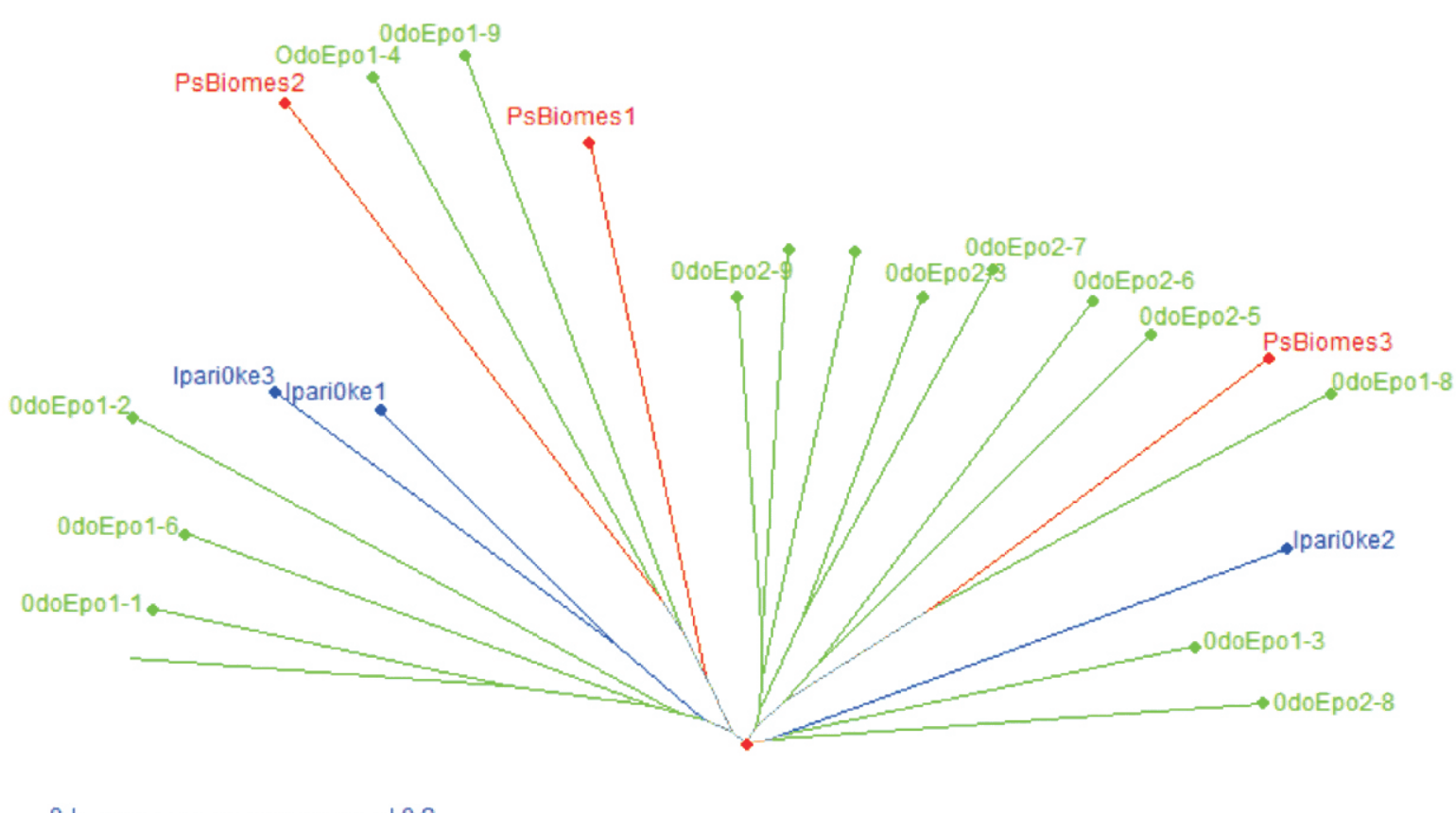
Code name: Ep 1- Odo-Epo farm 1; Ep 2- Odo-Epo farm 2; Ip - Ipari-Oke farm; Ps - PS Biome

\section{DISCUSSION}

Microsatellite markers are locus-specific, inherited as codominant, the mutation in the areas of a microsatellite is abundant, based on PCR and amplifying the genes does not need much DNA with very desirable quality which is useful to perform genetic research such as: determining the genetic mapping population genetic, phylogenetic, pedigree analysis and even forensic backrounds (Ghassemi Khademi, 2011) Simple Sequnds (Glasse (SSR) analysis in worke Repeats (SSR) analysis in worker bee populations Apis mellifera adansonii collected from four different locations of bee farms in parts of Ijebu Local Government Area has indicated that the expected heterozygosity $(\mathrm{He})$ levels vary with the various locations. This was also observed in Shannon's index value (I) which indicated some level of diversity in the population.

Coincidentally, I value of Ipari Oke $1(0.201)$ and Coinc Epo1-3 (0.167) populations (Table 2) were Odo Epol-3 (0.167) popul Whe (Table 2) higher than that of the others. When (he comparison was made at the population level, Ipari-Oke 1 had the highest gene diversity of 0.190 and Shannon's index, second to that were observed for the OdoEpo1-3 populations. The highest genetic diversity in Ipari-Oke1 population could have most likely resulted from having favourable climatic and vegetative conditions for extensive queen bee breeding and bee transfer during human settlements and farming activities from many other provinces thereby possible introgressions of genes and interbreeding.

However, the worker bee samples showed distinctiveness in their population and this could be due to the introduction of new alleles through drones from different colonies mating with the queen during the mating season. Also, the migratory pattern of honeybees introduces different genotypes could also contribute to the divergence of genes. This is following Tunca \& Kence (2011)

The primer A29 could be said to be the most informative marker and most suitable as all samples were amplified and the alleles were fully expressed.

The dendrogram illustrated that although the worker bee samples belong to a single genetic ancestor, the genetic composition varied considerably among individuals. This may be due to their breeding pattern which includes several drones mating with a queen while on a matting flight, domestication whereby the farmer splitting the hives and a drone brood is introduced to anothe colony and swarming.

Ipari-Oke3 and Odo-Epo 1-8 populations diverged from all other populations (Figure 3 ) which showed they were closer in genetic distances than the others, these showed some level of inbreeding and formation of new genes, this is following finding of Rattanawannee et al. (2019) in Thailand hon Ratee populations. Ipari-Oke 19 5 were 5 were newly observed subcluster which represent another subspecies as they could have containe genes that are not common to others due to the flor they were feeding on, developed beekeeping and imported bee colonies from different origins to this territory so that there are different races of bees in the same area (Ostroverkhova et al., 2017). This, in turn, could have led to the formation of a new subspecies and heterogeneous population. Thus, indicated that the SSR markers used were effective the effective the populations.

The Factorial Component Analysis (FCA) also indicated that Odo-Epo and Ipari Oke honeybee populations were closer than other population (figure 4). The PS Biome bees had gene pools of different levels of genetic dissimilarities; a similar result was observed on sampled populations of Turkey and Bulgarian bees (Ivanova et al., 2007).

The results of the current study, when compared to that of other genetic studies in bees in Russia Ostroverkhova et al., 2017) and Thailand (Rattanawannee et al., 2019), expressed the same level of heterozygosity and divergence in populations while a lower percentage of polymorphism and average heterozygosity were observed in Turkey (Ozdil et al., 2006; Tunca \& Kence, 2011) and Iran (Kence et al., 2009; Rahimi et al., 2016) bees populations using RAPD, mtDNA and microsatellite markers.

\section{CONCLUSION}

The genetic composition of worker bees of Apis mellifera adansonii in Ijebu environ investigated using simple sequence repeat (SSR) revealed variations in the genetic makeup of the populations, no two individual of the entire population had the same genetic makeup, yet they all belonged to a single genetic linage. The data presented here showed that SSR markers were effective in discriminating honeybee populations, detecting the 
variability levels among populations. These results should be considered in conservation plans, particularly about moving of colonies and most importantly introducing bees of foreign origin and distributing queen bees from one centre to all over the country which will homogenize the gene pools of the populations.

This also serves as a baseline for genetic studies in documenting the genetic diversity of the $A$. . (t) using SSR marker. Also, it is suggested that other molecular tools such as ISSR, mtDNA and AFLP be used to access the genetic diversity of the honeybees in the study area to have a comprehensive database and preserve the genetic diversity of Apis mellifera.

\section{ACKNOWLEDGMENT}

The authors will like to thank the management of Olabisi Onabanjo University, Ago-Iwoye for approving to conduct this research. We will also like to appreciate the honey bee farmers for accepting of using their apiaries for the research. Our gratitude also to Mr Tunde Oreyemi for linking us up with the honeybee farmers and volunteering to accompany us to all the bee farms.

\section{REFERENCES}

Abdullahi, G., Sule, H., Chimaya, I. A. \&Isah, M. D. (2011). Diversity and relative distribution of Honeybees foraging plants in some selected reserves in Mubi region, Sudan Savannah zone of Nigeria. Advances in Applied Science Research. 2 (5):388395.

Abou-Shaara, H. F, Draz, K. A., Al-Aw, M., \& Eid, K. (2012). Stability of honeybee morphological characters within open populations. Uludag Bee Journal, 12 (1):31-37.

Ajao, A. M. (2012). Comparative Studies on Ecology and Morphometrics of Reared and Feral Honeybees in Geological Zones of Kwara State, Nigeria. PhD Thesis. Federal University of Agriculture, Abeokuta.

Akunne, C. E., Akpan, A. U. \& Ononye, B. U. (2016). A pattern of nectariferous plant diversity of African honeybee (Apis mellifera adansonii L.) in Awka and Agulu Environs, Southeast Nigeria. Journal of Apiculture, 31 (4):281-291.
Alaux, C., Le Conte, Y. \& Decourtye, A. (2019). Pitting wild bees against managed honey bees in their native range, a losing strategy for the conservation of honey bee biodiversity. Frontiers in Ecology and Evolution, 7:60.

Arias, M. C., Brito, R. M., de Oliveira Francisco, F., Moretto, G., de Oliveira, F. F., Silvestre, D. \& Sheppard, W. S. (2006). Molecular markers as a tool for population and evolutionary studies of stingless bees. Apidologie, 37 (2):259-274.

Batra, S.W.T. (1995). Bees and pollination in ou changing environment. Apidologie, 26 (5):361-370

Fasasi, K.A. (2018). Microbiota of Honeybees Apis mellifera adansonii (Hymenoptera: Apidae) from selected Ecozones, South West Nigeria. Pakistan Journal of Biological Sciences. 21:232-238.

Fasasi, K. A.\& Afolabi, M. A. (2019). Comparative study of forage plants by Apis mellifera adansonii (Hymenoptera: Apidae) in Osu State, Nigeria. Journal of Applied Sciences. 19:121-127

Hunt, G. J.\&Page, R. E. (1992). Patterns of inheritance with RAPD molecular markers reveal novel types of polymorphism in the honeybee. Theoretical and Applied Genetics, 85 (1):15-20

Ivanova, E., Ivgin, R., Kence, M. \& Kence, A (2007). Determination of genetic variation and differentiation in honeybees of Turkey and Bulgaria. $1^{\text {st }}$ Balkan Countrie Beekeeping Congress and Exhibitio Abstracts p47. 29 March-1 April 2007, İstanbul, Türkiye

Ivanova, E., Staykova, T. \& Petrov, P. (2010) Allozyme variability in populations of local Bulgarian honeybee. Biotechnology and Biotechnological Equipment, 24 (2): Biotechnolog 371 -374.

Kence, M., Farhoud, H.J. \&Tunca, R.I. (2009) Morphometric and genetic variability of honeybee (Apis mellifera L.) population from northern Iran, Journal of Apicultural Research, 48 (4): 247-255.

Kumar, N. S. \& Gurusubramanian, G. (2011). Random amplified polymorphic DNA (RAPD) markers and its applications. Science Vision, 11 (3): 116-124.
Lewontin, R. C. (1972). The apportionment of human diversity. Evolutionary Biology, 6: 381-398.

Michener, C. D. (2013). The meliponini Pot-honey, Springer. 3-17.

Miller, M.P. (1997). Tools for population genetic analyses (TFPGA) 1.3: A Windows program for the analysis of allozyme and molecular population genetic and Computer software distributed by the author. Department of Biological Sciences, author. Department of Biological Sciences, Nothern Arizona University, Flagstaff, AZ.

Murray, M. G. \& Thompson, W. F. (1980). Rapid isolation of high molecular weight plant DNA. Nucleic Acids Research, 8:43214325

Nei, M. (1973). Analysis of gene diversity in subdivided populations. Proceedings of the National Academy of Sciences. USA, 70: 3321-3323.

Oldroyd, B. P. \& Fewell, J.H. (2007). Genetic diversity promotes homeostasis in insect colonies. Trends Ecology Evolution, 22 (8): 408-413.

Oluwaseun, T. O. (2009). Economics of honey production in International Journal of Entomology Research 35 Ijebu Division of Ogun State. Unpublished M.Sc. Thesis, Olabisi Onabanjo University, Ogun State, Nigeria.

Ostroverkhova, N.V., Kucher, A.N., Konusova, O.L., Kireeva, T.N. \& Sharakhov, I.V. (2017) Genetic diversity of honeybees in different geographical regions of Siberia, International Journal of Environmental Studies, 74 (5):771-781.

Ozdil, F., Yıldız, M.A., Meydan, H. \& Gençer, H.V. (2006). Genetic structure of Turkish honeybee populations based on RAPD and mtDNA RFLP markers. Proceedings of The Second European Conference of Apidology (edited by Vladimir Vesely and DaliborTitera) p.53.10-14 September. DaliborTitera) p.53.10
Prague, Czech Republic.

Peakall, R. \& Smouse, P. E. (2006). GENALEX 6: genetic analysis in Excel. Population genetic software for teaching and research Molecular Ecology, 6: 288-295.

Rahimi, A., Miromayedi, A., Kahrizi, D., Abdolshahi, R., Kazemi, (2014). Microsatellite genetic diversity of
Apis mellifera medaskorikov. Molecular Biology Reports, 41,7755-7761.

Rahimi, A., Mirmoayedi, A., Kahrizi, D., Zarei, L. \& Jamali, S. (2016). Genetic diversity of Iranian honeybee (Apis mellifera meda Skorikow, 1829) populations based on ISSR markers. Cellular and Molecular Biology, 62 (4): 53-58.

Rattanawannee, A., Duangphakdee, O., Chanchao, C., Teerapakpinyo, C., Warrit, N. Wongsiri, S., \& Oldroyd, B. P. (2019). Genetic Characterization of Exotic Commercial Honey Bee (Hymenoptera: Apidae) Populations in Thailand Reveals High Genetic Diversity and Low Population Substructure. Journal of Economic Entomology, 113 (1):34-42.

Rinderer, T. E., Oldroyd, B. P., Wongsiri, S., Sylvester, H. A., De Guzman, L. I., Stelzer, J. A., \& Riggio, R. M. (1995). A morphological comparison of the dwarf honeybees of southeastern Thailand and Palawan, Philippines. Apidologie, 26 (5): 387-394.

Rohlf, F.J. (2000). NTSYS-pc numerical taxonomy and multivariate analysis system, version 2.20e. Exeter Publication, New York.

Sheppard, W.S. \& Meixner, M.D. (2003) Apis mellifera pomonella, a new honeybee subspecies from Central Asia. Apidologie 34:367-375.

Solignac, M., Vautrin, D., Loiseau, A., Mougel, F. \& Baudry, E., (2003). Five hundred and fifty microsatellite markers for the study of the honey bee (Apis mellifera L.) genome. Molecular Ecology Notes, 3: 307-311

Strange, J. P., Garnery, L., \&Sheppard, W. S. (2008). Morphological and molecular characterization of the Landes honeybee (Apis mellifera L) ecotype for genetic conservation Journal of Insect Conservation, 12 (5): 527-537.

Tunca, R.I. \& Kence, M. (2011).Genetic diversity of honeybee (Apis mellifera L.: Hymenoptera: Apidae) populations in Turkey revealed by RAPD markers. African Journal of Agricultural Research, 6 (29): 6217-6225.

Whitfield, C. W., Behura, S. K., Berlocher, S. H., Clark, E. G., Johnston, J. S., Sheppard, W. S., Smith, D. R., Suarez, A. V., Weaver, D. 
\&Tsutsui, N. D. (2006) Thrice out of Africa:

ancient and recent expansions of the honey

bee, Apis mellifera. Science 314 (5799):

642-645.

Woodley, S., Mackinnon, K., McCanny, S., Pither, R., Prior, K., Salafsky, N. \& Lindenmayer, D. (2015). Managing protected areas for biological diversity functions Protected Area Governance and Management: ANU Press.

Yeh, F.C., Yang, R. \& Boyle. T. (1999). POPGENE

1.32: Microsoft Windows-based freeware

for population genetic analysis. University

of Alberta, USA. 